$1-1-1944$

\title{
Tests of four nitrogen-carriers in a mature apple orchard at Martinsburg, West Virginia
}

\author{
R. H. Sudds
}

Follow this and additional works at: https://researchrepository.wvu.edu/ wv_agricultural_and_forestry_experiment_station_bulletins

\section{Digital Commons Citation}

Sudds, R. H., "Tests of four nitrogen-carriers in a mature apple orchard at Martinsburg, West Virginia" (1944). West Virginia Agricultural and Forestry Experiment Station Bulletins. 315.

https://researchrepository.wvu.edu/wv_agricultural_and_forestry_experiment_station_bulletins/317 @ WVU. It has been accepted for inclusion in West Virginia Agricultural and Forestry Experiment Station Bulletins by an authorized administrator of The Research Repository @ WVU. For more information, please contact ian.harmon@mail.wvu.edu. 
West Virginia University Libraries

308021008961253 



\title{
Tests of Four Nitrogen-Carriers
} in a Mature Apple Orchard at Martinsburg, West Virginia by

R. H. Sudds

\author{
Agricultural Experiment Station \\ College of Agriculture, Forestry, and Home Economics \\ West Virginia University \\ C. R. Orton, Director
}





\title{
TESTS OF FOUR NITROGEN-CARRIERS IN A MATURE APPLE ORCHARD AT MARTINSBURG, WEST VIRGINIA
}

\author{
R. H. Sudds
}

\section{HISTORICAL}

The previous report on the fertilization of apple orchards in West Virginia was written in 1932 by Knowlton and Hoffman (9). In 1922, when the experiments described in that bulletin were started, only two fertilizers with quickly available nitrogen, nitrate of soda and sulphate of ammonia, had attained sufficient importance to warrant testing their comparative value. The results presented by Knowlton and Hoffman indicated that when nitrate of soda and sulphate of ammonia were applied 15 days before bloom, the response was practically the same from either material. When the applications were niade at time of bloom, the nitrate of soda gave the greater response. Several years after that test was begun, new kinds of nitrogen fertilizers, such as cyanamid and urea, became of some consequence. It was decided then that the orchard response resulting from the use of these two materials should be compared with that obtained from sulphate of ammonia and Chilean nitrate of soda.

The newer fertilizer tests ${ }^{1}$ were begun in 1936 in a commercial apple orchard situated near Martinsburg, West Virginia, in the northern end of the Shenandoah Valley. The purpose was to compare the effects of the four nitrogen-carriers-Chilean nitrate of soda, sulphate of ammonia, cyanamid, and urea-on the growth and yield performance of 25-year-old York Imperial apple trees. The experiment was concluded after the 1943 season at the end of the 8-year period.

\section{DESCRIPTION OF THE ORCHARD}

The orchard is situated on a low, wide-based spur of Apple Pie Ridge which in this location is scarcely to be recognized as a hill. The major slope to the southeast rarely exceeds two percent in the experimental area. The elevation above sea level is approximately 630 feet. Three-quarters of a mile to the northwest, North Mountain rises abruptly to a height of 1000 feet above the

1. The following former or present staff members of the West Virginia Agricultural Experiment Station have assisted in the conduct of this experiment: Edwin Gould of the Department of Entomology; L. P. Batjer, R. S. Marsh, D. S. Brown, and O. E. Schubert of the Department of Horticulture. 
orchard, furnishing considerable protection against winds from the west and north.

The soil in the orchard is a Frankstown gravelly silt loam, which was formed by the weathering in place of highly impure limestone containing interbedded limey shales and fine-grained sandstone. This type, together with the Frankstown silt loam, into which it grades imperceptibly, is used extensively for apple and peach orcharding. The soil drainage, both surface and internal, is excellent. In this location the soil contained 25 to 35 percent gravel by weight. No rock outcrops or stones were present. Apple roots were found to penetrate to bedrock, which was encountered at 8 feet in one test excavation made in this orchard $(4$, p. 18).

Before the setting of the trees, the area was utilized for more than 100 years for the production of general farm crops. After planting in 1911, the orchard was intercropped with corn until the growth of the trees made the practice unprofitable.

For some years before the experiment, the orchard soil was not cultivated. The soil treatment during that period is most accurately described as that of practically none at all. When intercropping was abandoned, a volunteer cover of bluegrass and weeds came in; no encouragement was offered such as liming, seeding, or fertilizing.

There is no record of the application of lime to the orchard. Stable manure, chiefly from the dairy herd, is said to have been the only fertilizer applied to the area. Apparently it was not used in very substantial amounts.

Pruning was under supervision of the owner of the orchard and was done by his farm help. The training of the trees was about as expected in orchards of that age, while the pruning was below average in quality. Before the experiment, the only orchard operations practised with diligence were pruning and picking. Practically nothing else was done in the orchard.

\section{Spraying in the Orchard}

Before 1936, spraying was seldom done in the orchard. From the beginning of the experiment in that year through the season of 1942 , the spray schedule was approximately the same, as follows: Delayed dormant: 4 percent oil plus $1 / 2$ percent tar oil; pink, lime-sulphur 1 to 50 ; petal fall, lime-sulphur 1 to 50 , lime 6 pounds, plus 3 pounds of arsenate of lead per 100 gallons. During that period, all spraying was discontinued after the petalfall application. ${ }^{2}$

2 This unusual spray program was required by a second project, the biological and mechanical control of the codling moth, in progress concurrently in the orchard. 
The same schedule was followed during the 1943 season up to and including the petal-fall. After this application, 5 cover sprays were applied, with oil and nicotine in two of these sprays. A $1 / 4-1-100$ Bordeaux plus 3 pounds of lead arsenate per 100 gallons was used in all the cover sprays in 1943 .

All spraying was done under the direction of Mr. Edwin Gould, Associate Entomologist in Charge, University Experiment Farm, Kearneysville.

\section{PROCEDURE}

The York Imperial apple trees were set $34^{\prime} \times 36^{\prime}$ in 1911; they were 25 years old when the tests were started.

In 1936, before the nitrogen-carriers were applied, the ground cover was grubbed as shallowly as possible from directly under the spread of the branches of all the trees in the block. ${ }^{3}$ The resultant roughly-circular cleared area averaged slightly less than 10 feet in radius about the trunk of each tree. In 1937, the occasional small spots of grass and weeds appearing in the cleared areas were merely mowed by hand. The vegetal cover never reappeared in any appreciable part of the cleared areas.

The $\mathrm{pH}^{4}$ of the surface 6 inches of the soil under the spread of the branches of the experimental trees varied a few hundredths around an average of 5.47 in 1936, when the nitrogen-carrier test was begun.

The organic content of the soil ranged from 1.8 to 2.7 percent with an average of 2.1 percent as determined by the IVakley and Black rapid-combustion method (13).

Four nitrogen-carriers-sulphate of ammonia, Chilean nitrate of soda, cyanamid, and urea-had been chosen for each trial. It was decided that each material should be applied to each of 20 trees. To select these, a section of 109 trees was divided into three classes on the basis of their trunk circumferences. These three classes in turn were subdivided into lots of four trees with their trunks more closely sized than in the first grouping. The selection of the individual trees within the group of four to receive each nitrogen-carrier was made by chance, except that no two trees receiving the same material were permitted to be closer than on a diagonal.

This arrangement gave 20 single-tree plots for each carrier. No buffer or guard trees were used between the fertilized individuals. To use such trees would liave practically doubled the

\footnotetext{
3 This was a requirement of the second research project, to which reference has been made.

${ }^{4}$ In the $\mathrm{pH}$ scale, 7 is neutral. Numbers below 7 indicate acidity. The greater the variation below 7, the stronger the acidity, which increases much faster than the numbers indicate.
} 
00000000

$000000 \frac{1}{4}$

0000000

$000 \otimes 000$

$00000 \otimes 0$

0000000

$00 \otimes 0 \otimes 00$

0000000

$0000 \otimes 00$

$00 \otimes 0 \otimes 00$

0000000

$00 \otimes D \otimes 00$

0000080

0000000

0000000

0000000

$0 \otimes 00000$

$000 \otimes \otimes 00$

$00000 \otimes 0$

$00 \otimes 0000$

0000000

$000 \otimes 000$

$00 \otimes 0000$

0800000

$0 \otimes 0 \otimes 000$

$000 \otimes 0 \otimes 0$

0008200

0000000

000800

000

3

0

$\cong$

$\overline{\mathrm{m}}$

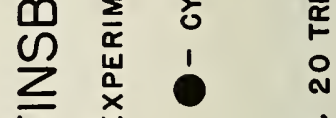

E

尔

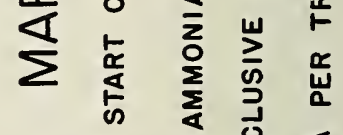

m文㟔总

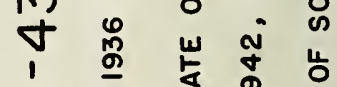

0 更

ติ

Q 0 के की

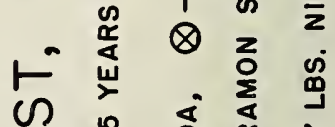

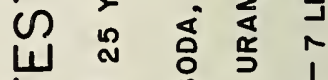

$\vdash$ क क

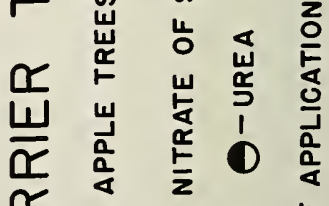

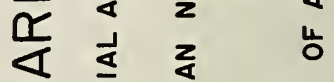

U

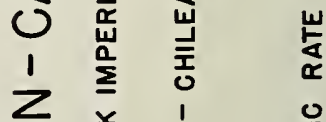

岁

옴

点

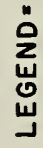


number required, and their use has not been found to be indispensable here or elsewhere $(5$, p. 23).

At the beginning of the experiment, the average trunk circumferences of the four groups of trees were: sulphate of ammonia, 893 millimeters ${ }^{5}$; nitrate of soda, $899 \mathrm{~mm}$; cyanamid, $890 \mathrm{~mm}$; and urea, $897 \mathrm{~mm}$.

No previous yield records of any kind were available; hence it was not possible to employ this most valuable measure of tree performance as a criterion in selecting or discarding trees.

No check or unfertilized trees were included in the experimental lay-out, since the apple tree which does not receive nitrogen in some form or other, at least every few years, is seldom commercially profitable under conditions existing in the Shenandoah Valley. The unfertilized trees, to which reference is made later, were scattered through the experimental area; they were not suitable for use in the project.

\section{Rates and Method of Application of the Nitrogen-Carriers}

The basic rate of application of the nitrogen-carriers was 7 pounds per tree per year of Chilean nitrate of soda or its nitrogen equivalent in one of the other materials. This amounted to $51 / 4$ pounds of sulphate of ammonia and cyanamid and $2 \frac{1}{4}$ pounds of urea. In 1942 and 1943, Uramon (urea plus a conditioner) was substituted at the rate of $2 \frac{1}{2}$ pounds for the straight urea, since the latter was no longer on the fertilizer market.

The fertilizer was spread as uniformly as possible by hand, the spreading being done from the tips of the branches toward the trunk of the trees.

The spring applications of the nitrogen-carriers have been made from mid-March to mid-April with one exception, that of cyanamid, which was applied on February 1, 1938. The fall applications of cyanamid were made on October 25,1938 , September 26, 1939, and November 18, 1940. During the course of the experiment, blossoming time in the orchard has varied from the latter part of April to the early part of May.

525.4 millimeters equals one inch. 


\section{EXPERIMENTAL RESULTS}

\section{Yields in the Martinsburg Orchard}

Figure 1 shows the average yields per tree for each of the four nitrogen-carriers during the period 1936-1943, inclusive. There were no significant differences between any of the yields. While the trees receiving sulphate of ammonia apparently outyielded any of the other groups, the statistical treatment of the data showed that all the trees, regardless of the material they received, could have come from the same fertilizer treatment in so far as significant differences in yields were concerned.

\section{CHILEAN NITRATE- 91.1 BU.}

\section{SULPHATE OF AMMONIA-100.2 BU.}

\section{CYANAMID - $91.7 \mathrm{BU}$.}

\section{UREA (URAMON) - $94.0 \mathrm{BU}$.}

FIG. 1-Average yield per tree for period 1936-1943, inclusive. None of the differences is significant

The yield of the experimental orchard has averaged about $11 \frac{1}{2}$ bushels per tree per year. Since the trees are set $34^{\prime} \mathrm{x} 36^{\prime}$ on the square, this means that there are theoretically 36 trees per acre. The experinmental block, then, has produced at the rate of 400 bushels per acre for each year of the 8-year period. This production may not appear to be particularly impressive when it is known that a few apple orchards in Jefferson and Berkeley Counties have yielded better than 1000 bushels per acre for single-seasons. However, such yields are the rare exception, not the rule, in that area. 6

- A survey (12) conducted in the Cumberland-Shenandoah Region of Pennsylvania, Virginia, and West Virginia showed that for the 5-year period 1922-1926, inclusive, only 6 percent of the more than 400 bearing orchard blocks covered by the survey averaged more than three barrels (93/4 bushels) per tree per year. Abrahamsen (1) more recently has summarized production records of more than 200 orchards in the Eastern Panhandle of West Virginia. He found that apple trees in the age group of those in this test averaged annually from 163 bushels per acre (ages 26-30 yrs.) to 133 bushels per acre (ages 31-35). 


\section{Trunk Circumferences in the Martinsburg Orchard}

Trunk measurements are of some value in determining the response of fruit trees to fertilizers. In general, the larger the top, the larger the trunk. Also, the larger the trunk, the larger the yield will tend to be in most instances. Taken alone, without the corroboration of other data such as yields, trunk measurements must be used with great caution. When, however, as in this instance, both yields and trunk circumferences indicate exactly the same result, the latter are helpful.
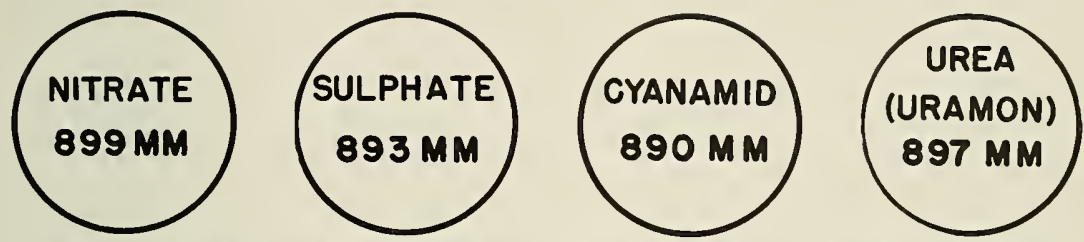

Fig. 2-Average trunk circumference in 1936 at start. Note uniformity of groups between carriers
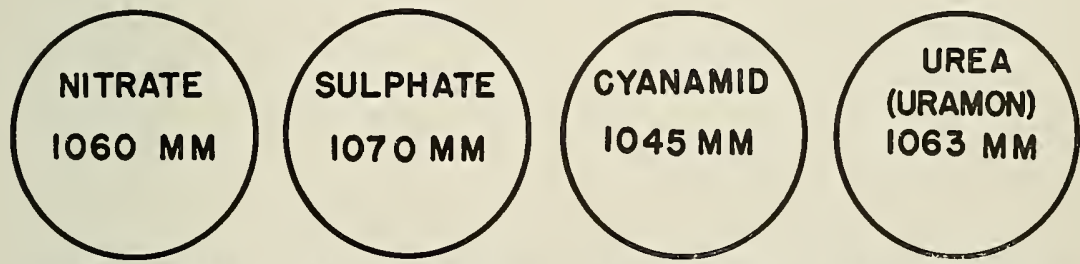

Fig. 3-Average trunk circumference in 1943 at end. Note continued uniformity of all groups. No significant differences observed

Figures 2 and 3 show diagrammatically the trunk circumferences before and after the experiment. A casual inspection of the values shows that the trees completed the 8-year period as they had entered it, with the four groups of trees closely alike at both times. The four lots of trees could hardly be expected to possess more uniform average trunk circumferences. None of the differences is significant.

Some Possible Explanations for the Uniform Response of the

Trees to all of the Nitrogen-Carriers

It will be observed that all four nitrogen-carriers have given equal response in growth and yield during the 9-year period; this 
agrees with the inconsequential differences obtained in orchard trials from the use of the nitrogen-carrying fertilizers-sulphate of ammonia and nitrate of soda-when nitrogen was the limiting factor and when amounts of fertilizer were used carrying approximately the same amounts of nitrogen $(5,7)$. Since the results of the present experiment which includes two other carriers, might have been somewhat different under other conditions, the factors promoting the observed uniform response should be considered briefly.

Anthony (2) found that when either nitrate of soda or sulphate of ammonia is applied early in the spring to apple trees in heavy bluegrass sod, the trees are able to get but little of the nitrogen. In this experiment, however, the sod and all other vegetal cover under the spread of the branches had been removed in 1936, before the tests were begun. The grass and weeds did not return to any appreciable extent during the entire 8-year period. Practically all the nitrogen in any form should have been available to the tree roots, since the carriers were applied almost exclusively to the area free of vegetation.

Another factor making for an equal response was that the slower-acting nitrogen-carriers-cyanamid, sulphate of ammonia, and urea or Uramon, as well as the quicker-acting nitrate of soda -were applied early each year, usually two weeks before bloom. The result of applying these materials at that time was that their nitrogen content could be changed to the nitrate form before the beginning of the heavy demand of the spring growth of the trees. Root activity proceeds at any time of the year when the soil is not frozen and when food and moisture are adequate.

Although the soil was quite acid, it would appear that the nitrification of the sulphate of ammonia took place with sufficient rapidity to furnish the nitrogen required by the trees. If the experiment had been continued for several years longer and no lime had been applied to the area under the branches, it is possible that the soil acidity would have become so great that the ammonia might not have been converted to the nitrate form quickly enough. In that event, the nitrogen requirements of the trees during the period of peak demand in the spring might not have been as well satisfied, and the response of those trees might have been appreciably less. 


\section{THE EFFECT ON SOIL ACIDITY OF APPLYING THE FOUR NITROGEN-CARRIERS FOR EIGHT SEASONS}

Before the treatments were started in 1936, samples were obtained from the surface 6 inches of soil under the spread of the branches of each tree in the experimental block. The sampling was repeated in each subsequent year, except in 1940.

As Figure 4 indicates, the $\mathrm{pH}$ values of all the samples were practically the same at the start, varying only slightly and insignificantly around an average $\mathrm{pH}$ of 5.47 .7 The differences were so small that duplicate samples might have reversed the order in which these rank, without affecting results.

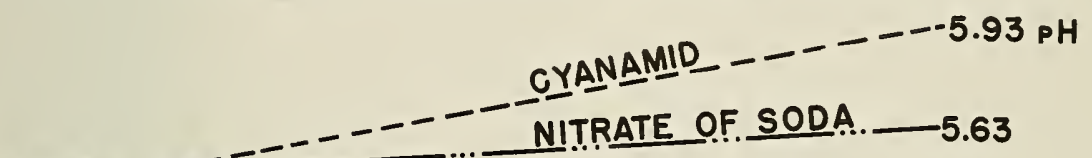

PH 5.4

$1936-$

BEFORE TEST

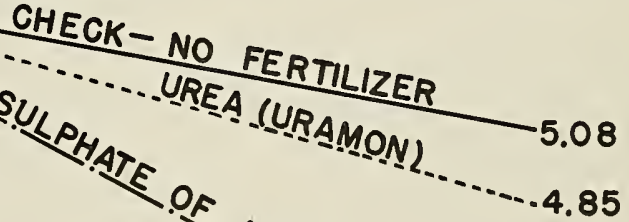




\section{Nitrate of Soda}

The effect of the nitrate of soda in decreasing the soil acidity is not as desirable as would at first seem to be the case. The sodium left as a residue when the nitrate is absorbed tends to break down the cementing material holding together the individual soil grains in the form of clusters or aggregates. Such soil is more likely to erode, since the particles act like individual grains of sand. Likewise, it becomes unduly sticky when wet and hard when dry. These effects were very pronounced in the soil samples taken in the fall of 1943. A report by Batjer and Sudds (3) based on an 11-year comparison of nitrate of soda and sulphate of ammonia in an orchard of the same general area and on the same soil series has demonstrated this effect from the nitrate.

Although the use of sodium nitrate does reduce the amount of lime needed to maintain a suitable soil reaction, it does not eliminate the necessity for liming, since the nitrate applied in rings for the trees can hardly be expected to benefit the vegetation between the tree rows. Calcium likewise is important in the nutrition of the tree.

More Chilean nitrate of soda is used in the orchards of the Eastern Panhandle than all other nitrogen-carriers combined. This situation appears to be largely a matter of habit and custom. The importance of the minor elements in Chilean nitrate of soda has been stressed unduly. With the amounts of nitrate commonly applied per acre and with the relatively small content of these accidental impurities in the Chilean product, the slight additions of these other salts are usually of no practical importance. Collison and Anderson (6) in a progress report on their investigations in New York observed that, so far, any special claims carried by the commercial grade of complete fertilizer, such as minor-element content or special value for fruit, have not been justified on the basis of production or quality.

\section{Cyanamid}

Where cyanamid was used, there was also a decrease in soil acidity. Figure 4 shows that this difference in reaction of the soil at the beginning and in 1943 was much greater than in the case of the nitrate of soda. This decrease is due to the lime contained by the cyanamid, a ton of which has the basic effect of 1260 pounds of limestone $\left(\mathrm{CaCO}_{3}\right)$. Since calcium accounts for the rise in the $\mathrm{pH}$ of the soil under cyanamid-treated trees, this decrease in acidity is of a more desirable character as com- 
pared with that resulting from the use of the Chilean nitrate of soda.

The maximum safe rate of application of cyanamid suggested for fruit trees on heavy soils possessing a normal amount of organic matter and soil moisture is 400 pounds per acre. This is the equivalent of 252 pounds of limestone $\left(\mathrm{CaCO}_{3}\right)$. While the effect of the cyanamid in this experiment has been to decrease the soil acidity under the trees, it is obvious that this had no effect on the soil reaction between the tree rows where the cyanamid was not applied. Most of the cover crop or sod is grown in this latter area, and liming may still be required there.

The use of cyanamid resulted in foliage scorch or burn in two years out of eight: 1937 and 1943. The leaf injury appeared in September 1937 and in June 1943, in both instances after March applications of $5 \frac{1}{4}$ pounds of cyanamid per tree. No scorch appeared in the case of any of the other nitrogencarriers tested, although all applications contained the same amount of nitrogen and were applied in the same manner and usually during the same day.

While the cyanamid injury appeared when the material was used at the theoretical rate of 187 pounds per acre, applying the cyanamid in the "rings" under the branches raised the actual rate for those areas to nearly 750 pounds per acre, twice the amount suggested by the manufacturers.

The burning observed in 1937 and 1943 evidently was a direct consequence of the dry soil existing at the time of each application and of a continued dry spell for about a month afterwards. In the intervening period, the cyanamid probably was converted in part to a form toxic when absorbed by the tree roots. Frozen soil might have resulted in the same type of injury to the foliage (8).

Amounts of cyanamid as great as 21 and 25 pounds per tree applied in rings did not necessarily produce injury with certain other trees in this orchard which were not part of the test. When scorch occurred, $5 \frac{1}{4}$ pounds produced injury to the foliage but in lesser amounts than the abnormally heavy applications. It was not possible to predict the appearance of the scorch.

For a complete discussion of the cyanamid injury as it was observed in 1937 and in 1943, two detailed reports by Sudds and Marsh $(10,11)$ should be consulted.

The yields of the trees receiving cyanamid have been the same as those receiving the other nitrogen-carriers. The foliage injury observed in 1937 produced no detectable decline in yields. This may be due in part to the fact that the burning did not appear until well on in September, when the growth for the season had long been completed. The appearance of foliage 
injury in 1943 was observed in June, when the crop was already on the trees. On this occasion, there was no apparent effect on the yield of fruit for 1943 or on the grade or size of the apples.

If cyanamid is to be applied to apple trees in West Virginia, the application should be made only in the autumn, when the soil moisture is more likely to be adequate than in the spring. The soil should not be frozen at the time. Furthermore, the cyanamid should be distributed over the whole square or triangle of soil in which the tree is standing and should not be concentrated under the spread of the branches, a practice which in effect raises the rate of application. The amount applied to fruit trees on heavy soils should be at most 400 pounds per actual acre of soil surface receiving this material. On sandy types of soil, 250 pounds of cyanamid per acre is the safe maximum, and it may be less for certain crops or conditions; injury will occur much sooner and the damage will be more severe on the lighter soils.

\section{Sulphate of Ammonia}

Sulphate of ammonia is used extensively for direct application in orchards over most of the state other than in the Eastern Panhandle.

In this experiment the application of sulphate of ammonia for 8 years has resulted in lowering the reaction of the soil under the trees by $1.2 \mathrm{pH}$ units. The average value under the branches reached 4.27 , and it should be recognized that this figure is much too low to permit the proper growth of any desirable species of ground cover in the area affected, if this was sought. The number and character of the fine roots likewise are unfavorably affected by such extreme acidity (3).

While the yields of the trees receiving the sulphate are higher than those of the other nitrogen-carriers under test, as Figure 1 shows, no significance should be attached to this difference. The wide natural variations in the productivity of the individual trees of all of the groups would require much greater average differences between treatments, before the yields due to the use of any of the materials could establish definite superiority.

The objectionable effect of the sulphate of ammonia in rapidly building up a high degree of soil acidity is a well-known property of this chemical. The use of this nitrogen-carrier should be accompanied every few years by the applicaton of at least the same total weight for the entire period in ground limestone or its equivalent in any other suitable form of lime. 
There is no question that ammonium sulphate is a satisfactory source of nitrogen for fruit trees when lime is used as indicated previously. The price paid for the sulphate should be sufficiently lower than that of the nitrate of soda to pay all expenses of labor and material of the liming. For that reason, the sales prices of nitrate of soda and sulphate of ammonia should not be compared solely on the basis of their relative nitrogen contents. This is the same recommendation issued previously by this Station (9).

\section{Urea or Uramon}

When the test was begun in 1936, urea was a source of nitrogen available for orchard use. Because of certain difficulties in storage and handling, urea as such disappeared from the market and the proprietary material Uramon partially replaced it. As constituted in 1943, Uramon was merely urea plus a conditioner added to improve the storage qualities which still were not ideal. The Uramon has resulted in tree growth and production equal to any of the other 3 nitrogen-carriers under trial. There is no doubt that urea is a perfectly satisfactory source of nitrogen for use in orchards under West Virginia conditions.

Uramon has increased the soil acidity a little less than half as much as has the sulphate of ammonia. The theoretical difference is much less than this (for 100 pounds of Uramon, 75 pounds of limestone, $\mathrm{CaCO}_{3}$, should be required to neutralize the acidity, while for 100 pounds of sulphate of ammonia, 110 pounds of limestone is required). Liming at the rate of threequarters of one pound of limestone for each pound of Uramon applied during any period under consideration is therefore necessary if it is desired to maintain the original soil reaction.

\section{Changes in pH Under Unfertilized Trees}

It is worth noting that the acidity under the half-dozen unfertilized trees which were scattered among those receiving the nitrogen increased from $\mathrm{pH} 5.47$ to 5.08-more than one-half of that resulting from the use of urea or Uramon. While only a very limited spray schedule was followed (as previously stated, this is a requirement of another project in progress in the same orchard), this practice is probably responsible for most of the increase in soil acidity under the unfertilized trees, because of the sulphur content of the material. 
At the close of the experiment, the average $\mathrm{pH}$ of four areas midway between the tree rows was 5.64. These had received practically no spray material and none of the nitrogen-carriers was applied in these places. The tendency for the soil to be more acid under the trees than beyond the tips of the branches is in agreement with some unpublished data in the possession of the author. With anything like a full spray schedule, it is probable than even the nitrate of soda and the cyanamid areas would have been more acid at the conclusion than at the beginning of the experiment.

\section{CONCLUSIONS}

Chilean nitrate of soda, sulphate of ammonia, and Uramon may be expected to produce equally satisfactory results as sources of nitrogen for direct application to apple trees in West Virginia, when lime is used as necessary with the sulphate and the Uramon for correcting soil reaction.

Cyanamid is safe for use as a nitrogen-carrier for direct application to apple trees in West Virginia orchards under a much narrower set of environmental conditions than Chilean nitrate, sulphate of ammonia, or Uramon. Cyanamid should preferably be applied in the autumn, when soil-moisture conditions are most likely to be favorable, but before the soil freezes. This nitrogen-carrier should not be applied in the usual fertilizer rings under the spread of the branches. The amounts per unit of soil surface recommended by the manufacturers should not be exceeded.

\section{SUMMARY}

Comparison of the growth and yield response of mature York Imperial apple trees to applications of four nitrogencarriers was begun in the spring of 1936 in a commercial orchard near Martinsburg, West Virginia, in the Shenandoah Valley portion of the Eastern Panhandle.

The basic application was 7 pounds of Chilean nitrate of soda or its nitrogen equivalent in sulphate of ammonia, cyanamid, or urea (Uramon). Each carrier was applied to 20 singletree plots in the spring except cyanamid in 1938, 1939, and 1940 , when fall-applications of this material were made. The trees were selected on the basis of uniformity of trunk circumferences, since no yield records were available.

At the close of the experiment after the 1943 season, there 
were no significant differences in yields for the 8-year period between any of the four nitrogen-carriers. The trunk circumferences, which averaged almost the same for all of the four groups at the start, were practically as close at the end.

The effect of each nitrogen-carrier on soil reaction is discussed briefly.

Any of the four materials tested will serve as a satisfactory source of nitrogen in apple orchards in West Virginia, if certain precautions are observed: (1) Lime should be used as necessary with the two carriers, sulphate of ammonia and Uramon, which tend to increase soil acidity. (2) As a precautionary measure, cyanamid should be applied in the autumn, not in the spring, and distributed over the entire tree squares or triangles.

While nitrate of soda would be expected to give a greater response in blossom-time applications, all of the materials were usually applied at least two weeks before bloom, so that the carriers with more slowly available nitrogen, such as sulphate of ammonia, Uramon, and cyanamid, performed to equal advantage. 



\section{LITERATURE CITED}

(1) Abrahamsen, M. A. 1943. Tree depreciation-for taxation. Mountaineer Grower 14(149): 5-9.

(2) Anthony, R. D. 1930. Sulphate of ammonia and nitrate of soda in a sod orchard. Penna. Agr. Exp. Sta. Bul. 249.

(3) Batjer, L. P., and Sudds, R. H. 1938. The effect of nitrate of soda and sulphate of ammonia on soil reaction and root growth of apple trees. Proc. Amer. Soc. Hort. Sci. 35:279-282.

(4) Browning, G. M., and Sudds, R. H. 1942. Some physical and chemical properties of the principal orchard soils in the Eastern Panhandle of West Virginia. W. Va. Agr. Exp. Sta. Bul. 303.

(5) Collison, R. C., and Anderson, L. C. 1936. Fertilizer experiments in the Morganthau orchard; Six years' results with nineteen treatments. New York (Geneva) Agr. Exp. Sta. Bul. 661.

(6) Collison, R. C., and Anderson, L. C. 1944. Comparison of complete fertilizers, especially commercial brands recommended for fruit, with nitrogen alone in demonstrational layouts in four counties of the Hudson Valley. 'Sixty-second Ann. Rep., New York State Agri. Exp. Sta., 44-45.

( 7) Gardner, V. R., Bradford, F. C., and Hooker, H. D. 1939. The fundamentals of fruit production. p. 251, McGraw-Hill.

(8) Hewetson, F. N. 1938. Cyanamid as an orchard fertilizer, Mich. Quart. Bul. 20:150-153.

(9) Knowlton, H. E., and Hoffman, M. B. 1932. The fertilization of apple orchards. III: A comparison of nitrate of soda and sulphate of ammonia. W. Va. Agr. Exp. Sta. Bul. 252.

(10) Sudds, R. H., and Marsh, R. S. 1939. Some results and suggestions regarding the use of calcium cyanamid on apples. Proc. Amer. Soc. Hort. Sci. $36: 36-40$.

(11) Sudds, R. H., and Marsh, R. S. 1944. Some further observations concerning injury to apple tree foliage induced by applications of calcium cyanamid. Proc. Amer. Soc. Hort. Sci. 43:25-28.

(12) Swinson, C. R., et al. 1927. Factors influencing the yield of apples in the Cumberland-Shenandoah Region of Pennsylvania, Virginia, and West Virginia. U. S. Dept. Agr. Tech. Bul. 54.

(13) Wakley, A., and Black, I. Armstrong. 1934. An examination of the Degtjareff method for determining soil organic matter and a proposed modification of the chromic acid titration method. Soil. Sci. 3\%:29-38. 

TABLE 1-Yield and Growth Performance in the Martinsburg orchard, 19361943, Inclusive (Continued)

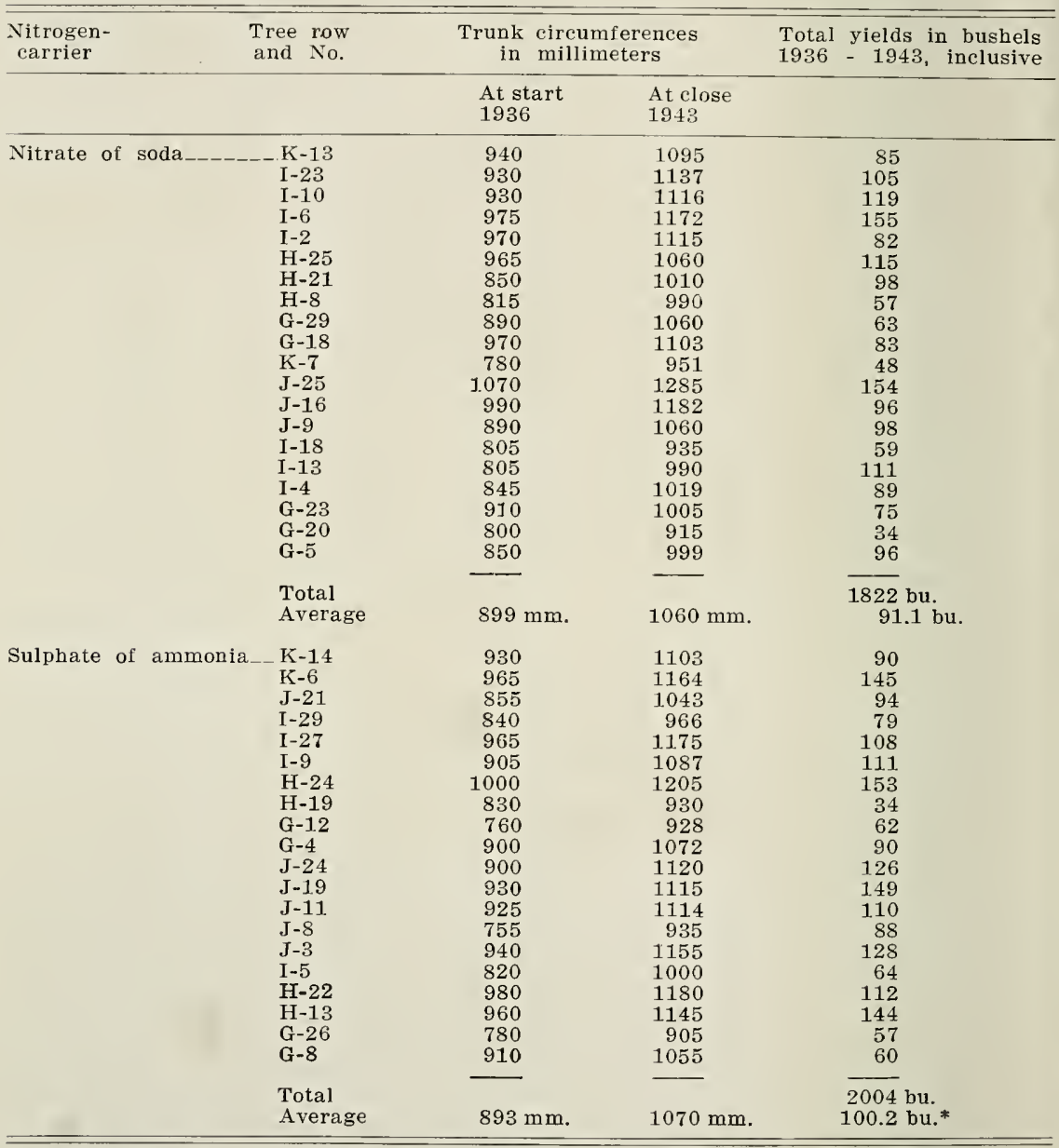

* The wide variation in individual yields, from 34 to 153 bushels, of the trees receiving sulphate of ammonia, together with a similar situation with the trees in the other three groups, results in no difference favoring the sulphate over any of the other treatments. 
TABLE 2-Changes in Average Soil pH Values in Areas Receiving the Nitrogencarriers in the Martinsburg Orchard, 1936-1943, Inclusive, as Determined Electrometrically with Glass Electrodes

\begin{tabular}{|c|c|c|c|c|c|c|}
\hline \multirow[b]{2}{*}{ Carrier } & \multicolumn{6}{|c|}{ YEAR } \\
\hline & $1936^{*}$ & 1937 & 1938 & 1939 & 1941 & $1943 \dagger$ \\
\hline Cyanamid & -5.42 & 5.48 & 5.40 & 5.24 & 5.87 & 5.93 \\
\hline Nitrate of soda & -5.44 & 5.44 & 5.45 & 5.20 & 5.62 & 5.63 \\
\hline Uramon & -5.49 & 5.14 & 5.21 & 4.48 & 4.71 & 4.85 \\
\hline Sulphate of ammonia & -5.47 & 4.88 & 5.03 & 4.10 & 4.29 & 4.27 \\
\hline Check-no fertilizer & -5.47 & & & & & 5.08 \\
\hline
\end{tabular}

Before start of experiment.

$\uparrow$ At close. 


